Military Technical College

Kobry El-Kobbah,

Cairo, Egypt.

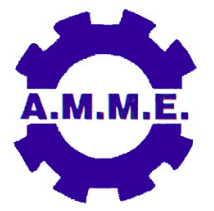

$17^{\text {th }}$ International Conference

on Applied Mechanics and

Mechanical Engineering.

\title{
EXPERIMENTAL DETERMINATION OF THERMAL PROPERTIES OF CHOPPED FIBER COMPOSITE MATERIALS
}

\author{
A. Saif ${ }^{*}, 1$, H. Kamal ${ }^{*}, \mathrm{KH}$. Shoukry*, O. Kamal ${ }^{*}$ and A.N. Zayed ${ }^{* *}$
}

\begin{abstract}
Thermal properties of chopped composites are important parameters for determining application and use of this category of materials. An experimental identification for thermal properties of different composite materials was conducted. In order to investigate the effect of fiber, three different chopped fibers with a phenol resin as a matrix; Carbon fiber, Basalt, and Fiberglass, were selected to determine their thermal properties. Also, the matrix is changed for carbon fiber; phenol resin and epoxy resin, to show the influence of matrix material. Two important parameters were investigated which are the thermal conductivity (TC) and the thermal expansion coefficient (CTE). For the four materials, the thermal conductivity obtained is very low with a range of $K$ $=0.159 \mathrm{w} / \mathrm{m}{ }^{\circ} \mathrm{C}$ for the Carbon / Phenol to $\mathrm{K}=0.1942 \mathrm{w} / \mathrm{m}{ }^{\circ} \mathrm{C}$ for the Carbon $/$ Epoxy, so those materials are used as thermal insulators. On the other side, thermal expansion coefficient has also very low negative values for the Phenol based composites with a range of $-146.6 \mu \mathrm{m} / \mathrm{m}^{\circ} \mathrm{C}$ for fiber glass / phenol to $-273.7 \mu \mathrm{m} / \mathrm{m}^{\circ} \mathrm{C}$ for carbon fiber / phenol, and for the Epoxy based composites the CTE has a low positive value which is $1049 \mu \mathrm{m} / \mathrm{m}^{\circ} \mathrm{C}$ for carbon fiber / epoxy .
\end{abstract}

\section{KEYWORDS}

composite, chopped fiber, thermal properties, thermal conductivity, thermal expansion, differential scanning calorimetry, modulated differential scanning calorimetry, thermoset polymers

\footnotetext{
* Egyptian Armed Forces;

** Professor, faculty of engineering, Heliopolis University, Cairo, Egypt.

1 Corresponding Author: ahmad safe@yahoo.com
} 


\section{INTRODUCTION}

Thermal properties of chopped composites are important parameters for determining application and use of this category of materials. These materials have excellent thermal properties of good heat transmission, low CTE they have been successfully uses in the manufacture of aviation engine nozzle and thermal assemblies of the firebox as well as brake discs for airplane in the aeronautical, astronautical, military, and civil fields [1-3]. These materials can also protect the space vehicle from the huge amount of heat produced by the friction of the atmosphere, with adsorbing the heat and avoiding its transfer to the interior parts [4-7].

The thermal conductivity of thermal insulations is usually measured using steadystate methods, e.g., guarded hot-plate (GHP) method [8], heat flow meter technique $[9,10]$, etc. These methods are well established, highly standardized, and reasonably precise in the temperature range from -50 to $600^{\circ} \mathrm{C}$. Obvious disadvantages of the steady state methods are the need for large samples and long measurement times. Rapid transient methods (e.g., flash method [11], hot-wire method [12], transient hot strip, transient hot-disc method $[13,14]$.

A so-called "three-point" (3P) method has been developed for thermal diffusivity measurements of thermal insulating materials [15].

In this work, an experimental identification for thermal properties of different composite materials was conducted. In order to investigate the effect of fiber, three different chopped fibers with a phenol resin as a matrix; Carbon fiber, Basalt, and Fiberglass, were selected to determine their thermal properties. Also, the matrix is changed for carbon fiber; phenol resin and epoxy resin, to show the influence of matrix material. Two important parameters were investigated which are the thermal conductivity (TC) and the thermal expansion coefficient (CTE). Results and conclusion are illustrated

\section{METHODOLOGY}

Thermal conductivity can be measured using several different instrumental techniques. One of these is based on differential scanning calorimetry (DSC). DSC is a thermal analysis technique, which measures heat flow into or out of a material as a function of temperature or time. DSC is primarily used to measure transition temperatures and associated heats of reaction in materials, particularly polymers. Measurement of glass transition temperature, melting point, percentage crystallinity, degree of cure, decomposition temperature, and oxidative stability are specific examples of some of the more common DSC measurements.

The most widely used approach for making DSC measurements is the heat flux DSC, in which the sample and reference materials (usually contained in metal pans) are placed on a thermoelectric disk inside a temperature programmed environment Figure 1. Heat flow in this approach is measured using the thermal equivalent of Ohm's Law where: $d Q / d t=d T / R ;(Q=$ heat, $t=$ time, $T=$ temperature, $R=$ thermal resistance of thermoelectric disk) $[16,17]$. 


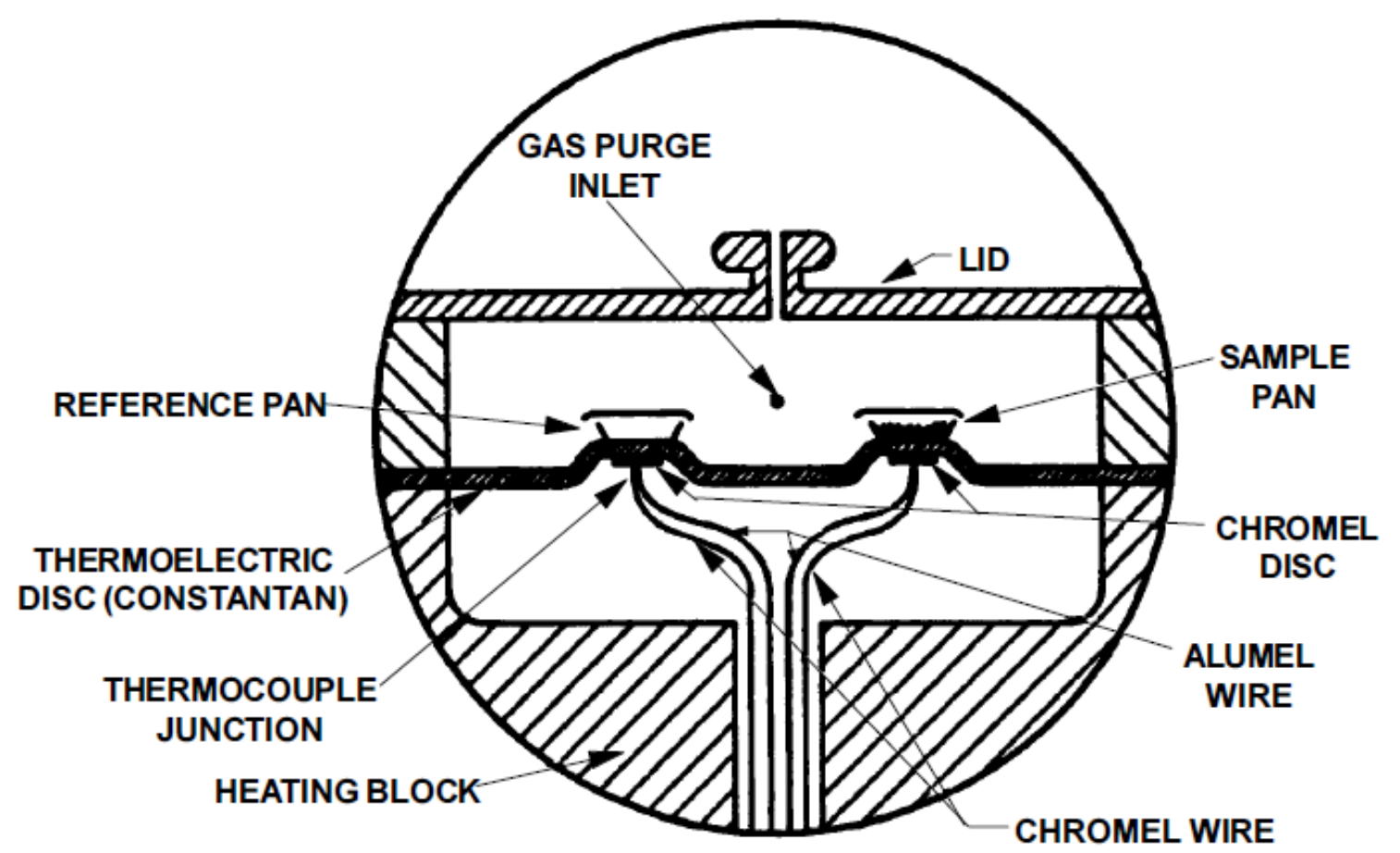

Fig. 1. Heat Flux DSC Schematic.

Determination of a material's thermal conductivity is important in evaluating its utility for a specific application. A variety of techniques is available to determine thermal conductivity including Modulated DSC. MDSC has the advantage of widespread availability due to its use in the study of the glass transition, melting temperature, crystallization, etc. of materials.

The thermal conductivity of the polymers is an important characteristic aiding device design. Often the desired thermal conductivity is in the range 0.7 to $3.5\left(\mathrm{~W} /{ }^{\circ} \mathrm{K} \mathrm{m}\right)$.

ASTM Method E1952 [18] describes the measurement of thermal conductivity by Modulated DSC. It is applicable to homogeneous, non-porous solid materials with a thermal conductivity in the limited range of 0.10 to $1.0\left(\mathrm{~W} /{ }^{\circ} \mathrm{K} \mathrm{m}\right)$ and a temperature range from 0 to $90{ }^{\circ} \mathrm{C}$.

The heat capacities of a thin and thick sample are measured with Modulated DSC [19-21]. When the thin sample is encapsulated in a pan of high thermal conductivity and subjected to a temperature modulation with long period, the sample has a uniform temperature distribution, and the measured specific heat capacity is the thermodynamic heat capacity of the sample. When the thick sample is exposed to a temperature modulation at one end, the measured apparent heat capacity is lower in comparison with the thin sample, because of the non-uniform temperature distribution across the height of the sample. The apparent heat capacity is proportional to the square root of the thermal conductivity of the sample, as shown by equation 1.

$$
K=\left(8 L C^{2}\right) /\left(C_{p} M d^{2} P\right)
$$


$\mathbf{K}$ is the observed thermal conductivity in $\mathbf{W} /(\mathrm{K} \mathrm{m}), \mathbf{C}$ is the apparent heat capacity in $\mathrm{mJ} / \mathrm{K}, \mathbf{C}_{\mathbf{p}}$ is the specific heat capacity in $\mathrm{J} /(\mathrm{g} \mathrm{K}), \mathbf{L}$ is the sample height in $\mathrm{mm}, \mathbf{M}$ is the thick sample mass in $\mathrm{mg}$, $\mathbf{d}$ is the sample diameter in $\mathrm{mm}$, and $\mathbf{P}$ is the modulation period in $\mathrm{s}$.

Using equation 1 the thermal conductivity of a sample is derived from the heat capacity measured on a sample and some geometric and experimental factors. If the thermal conductivity of the sample is low and approaches that of the surrounding purge gas, a correction to the observed thermal conductivity is necessary to compensate for heat loss through the sample side [21].

Thermal expansion coefficient also is very important factor in determining the application of the materials. Thermo-mechanical Analysis (TMA) is used to determine this coefficient.

\section{TEST RIG AND PREPARATION OF SAMPLES}

For identifying material thermal properties, four composite materials were studied experimentally. The steps conducted to achieve the thermal conductivity and thermal expansion are illustrated as follows

\section{Preparing the Composite Material Samples}

Four composite materials were selected to obtain their characteristics which are Basalt with phenol as a resin, Fiber glass with phenol as a resin, Carbon fiber with phenol as a resin and Carbon fiber with epoxy as a resin. It should be noted that these materials have a fixed volumetric mixing ratio between fiber and matrix which is determined previously from the end-user according to their mechanical properties. For the Carbone with Epoxy resin a mixture of fiber and resin was prepared and mixed together then cured under pressure only at normal temperature. For the three materials, it is mixed with the Phenol, a mixture of chopped fiber Figure 2 and resin was prepared and mixed together and then cured under pressure and temperature to obtain composite materials in the sheets shape of dimensions $300{ }^{*} 300^{*} \approx 3 \mathrm{~mm}$ in the cured stage as shown in Figure 3.
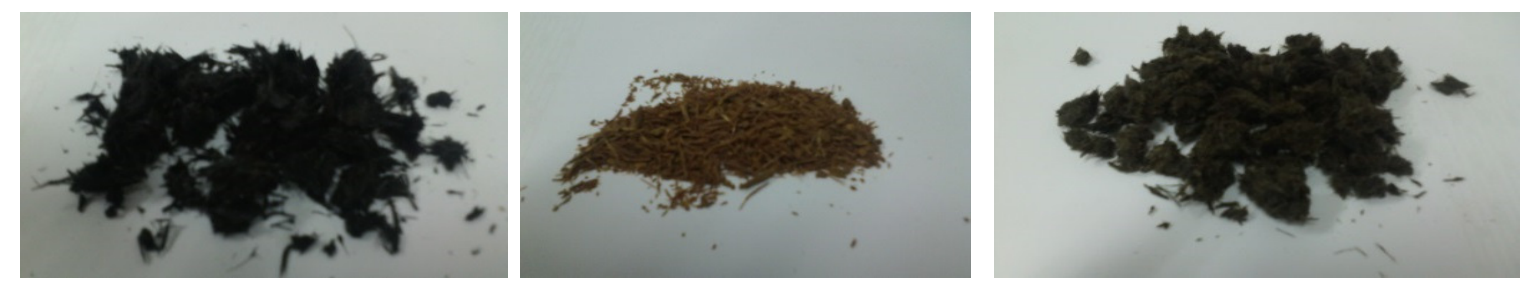

Fig. 2. Chopped Carbon fiber, Chopped Fiber glass and Chopped Basalt. 

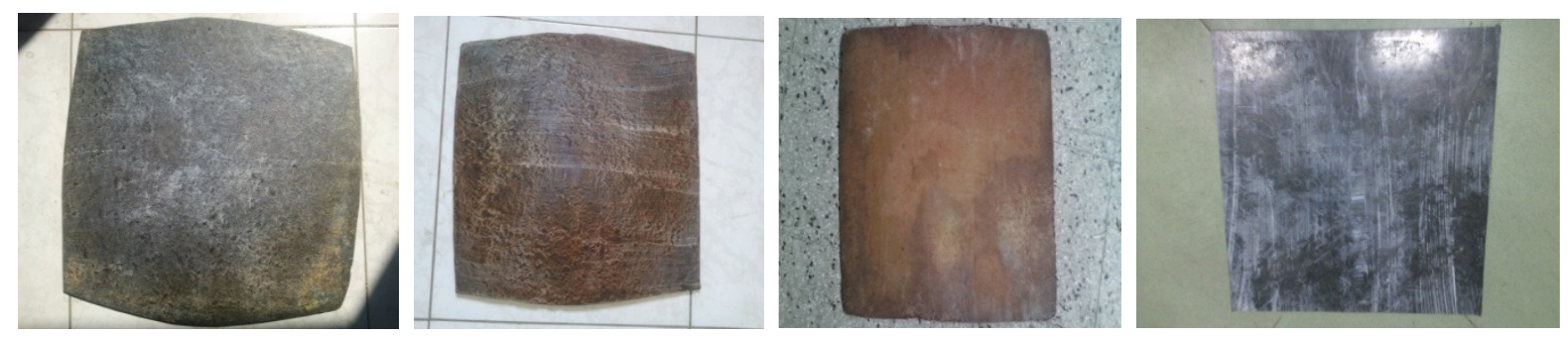

Fig. 3. Carbon fiber, basalt, Fiberglass and Carbon/epoxy sheets.

To obtain the thermal properties of these materials some tests might be done which are thermal conductivity measurement and determination of thermal expansion coefficient. Samples of diameters $5 \mathrm{~mm}$ was prepared to use with the DSC Q2000 apparatus to determine the thermal conductivity as shown in Fig 4.a and samples of $8^{\star} 8 \mathrm{~mm}$ is prepared to use with the TMA apparatus to determine thermal expansion coefficient as shown in Fig. 4.b.

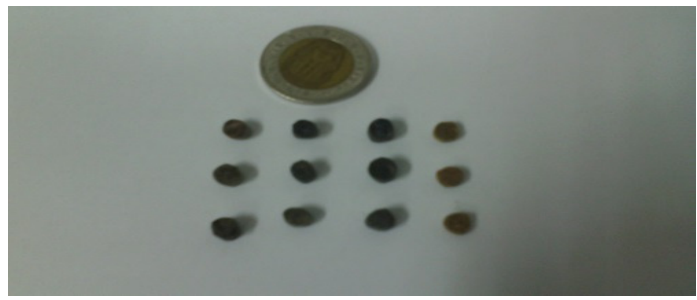

Fig. 4 a) samples for DSC

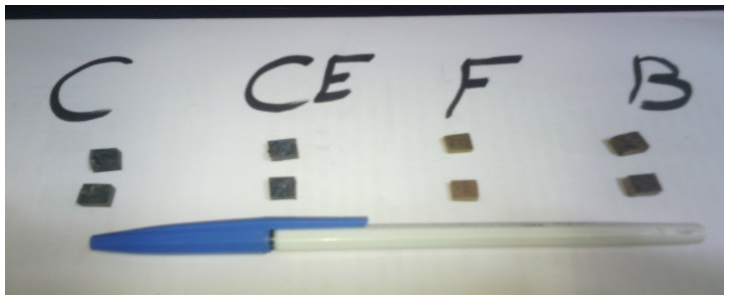

b) samples for TMA

\section{Test Machine}

\section{Differential scanning calorimetry (DSC) Q2000}

The Differential Scanning Calorimeter (DSC) determines the temperature and heat flow associated with material transitions as a function of time and temperature. It also provides quantitative and qualitative data on endothermic (heat absorption) and exothermic (heat evolution) processes of materials during physical transitions that are caused by phase changes, melting, oxidation, and other heat-related changes. This information helps the scientist or engineer identify processing and end-use performance. The DSC instrument works in conjunction with a controller and associated software to make up a thermal analysis system as shown in figure $(5 \mathrm{a})$.

\section{Performance of DSC- Q2000}

Temperature Range from -70 to $350^{\circ} \mathrm{C}$

Temperature Precision $+/-0.01{ }^{\circ} \mathrm{C}$

Sensitivity $0.2 \mu \mathrm{W}$

50-Position Auto-sampler Available

Pressure DSC Available (under nitrogen atmosphere) 


\section{Applications of DSC Q2000}

1) Identification of organic compounds and polymeric materials in which both first order (e.g., melting points).

2) It used to determine glass transition (second order).

3) It is used to determine crystallinity of the polymers. .

4) Determination of Heat Capacity

5) estimate purity

\section{Thermo Mechanical Analysis TMA Q400}

Thermomechanical Analysis remains one of the most basic tools of material science. The basis of TMA is the change in the dimensions of a sample as a function of temperature (TMA) as shown in figure (5 b).

\section{Performance of TMA Q400}

Temperature Range ambient to $900^{\circ} \mathrm{C}$

Temperature Precision $\pm 1{ }^{\circ} \mathrm{C}$

Maximum Sample Size - solid 26 mm (L) x 10 mm (D)

Sensitivity $15 \mathrm{~nm}$

Displacement Resolution $<0.5 \mathrm{~nm}$

Force Range 0.001 to $2 \mathrm{~N}$

Force Resolution $0.001 \mathrm{~N}$

Atmosphere (static or controlled flow) nitrogen.

\section{Application of TMA Q400}

Determine coefficient of thermal expansion (CTE).

\section{Test Method}

For the DSC the Conventional MDSC method is used with time period of 20 seconds and the temperature started from $0{ }^{\circ} \mathrm{C}$ to $300{ }^{\circ} \mathrm{C}$. For the TMA the ramp method is used and temperature started from $25{ }^{\circ} \mathrm{C}$ to $800{ }^{\circ} \mathrm{C}$.

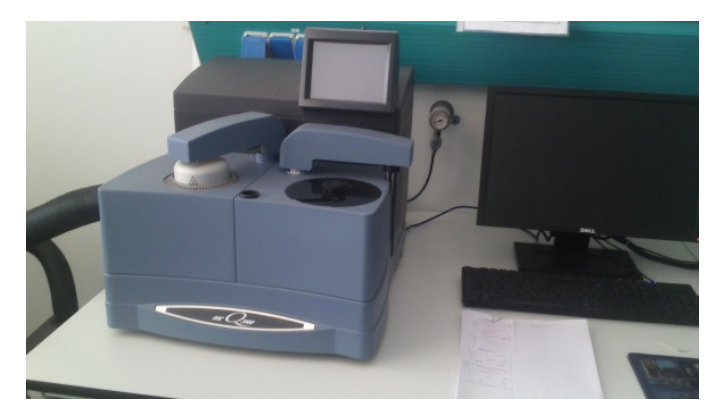

Fig 5 a) DSC Q2000

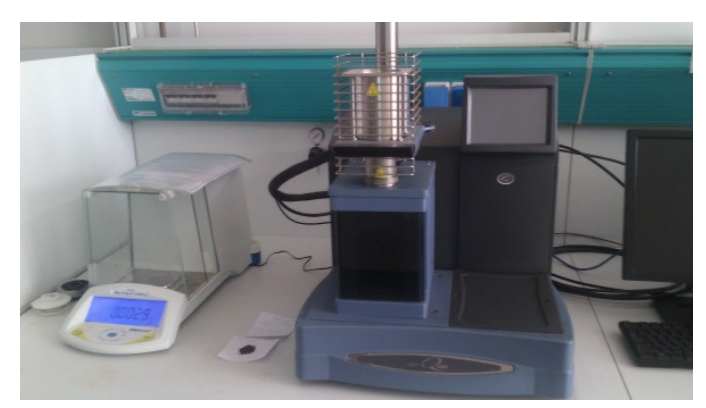

b) TMA Q400 


\section{RESULTS}

For the thermal conductivity the following Table 1 summarizes the values obtained from the test to the four selected materials and the values of the specific heat for those materials are shown in figures 6:9.

Table 1 Thermal conductivity for the selected materials.

\begin{tabular}{|l|c|}
\hline \multicolumn{1}{|c|}{ Composite type } & $\mathrm{K}\left(\mathrm{w} / \mathrm{m}^{\circ}{ }^{\circ} \mathrm{C}\right)$ \\
\hline Basalt / phenol & 0.1720 \\
\hline Fiber glass / phenol & 0.1846 \\
\hline Carbon / phenol & 0.1590 \\
\hline Carbon / epoxy & 0.1942 \\
\hline
\end{tabular}

From the results shown above it is noticed that the range of the thermal conductivity is very low, so all of this materials are used as insulators. Carbon Fiber with a phenol resin is the lowest value of thermal conductivity among these materials with $\mathrm{K}=$ $0.159 \mathrm{w} / \mathrm{m}{ }^{\circ} \mathrm{C}$ and the carbon fiber with epoxy resin is the highest value of thermal conductivity with $\mathrm{K}=0.1942 \mathrm{w} / \mathrm{m}{ }^{\circ} \mathrm{C}$. Compared with the published values of the thermal conductivity of the polymers [22] which are in the range of 0.17 to $0.14 \mathrm{w} / \mathrm{m}$ ${ }^{\circ} \mathrm{C}$ we find that the selected chopped composite materials have similar thermal conductivities values.

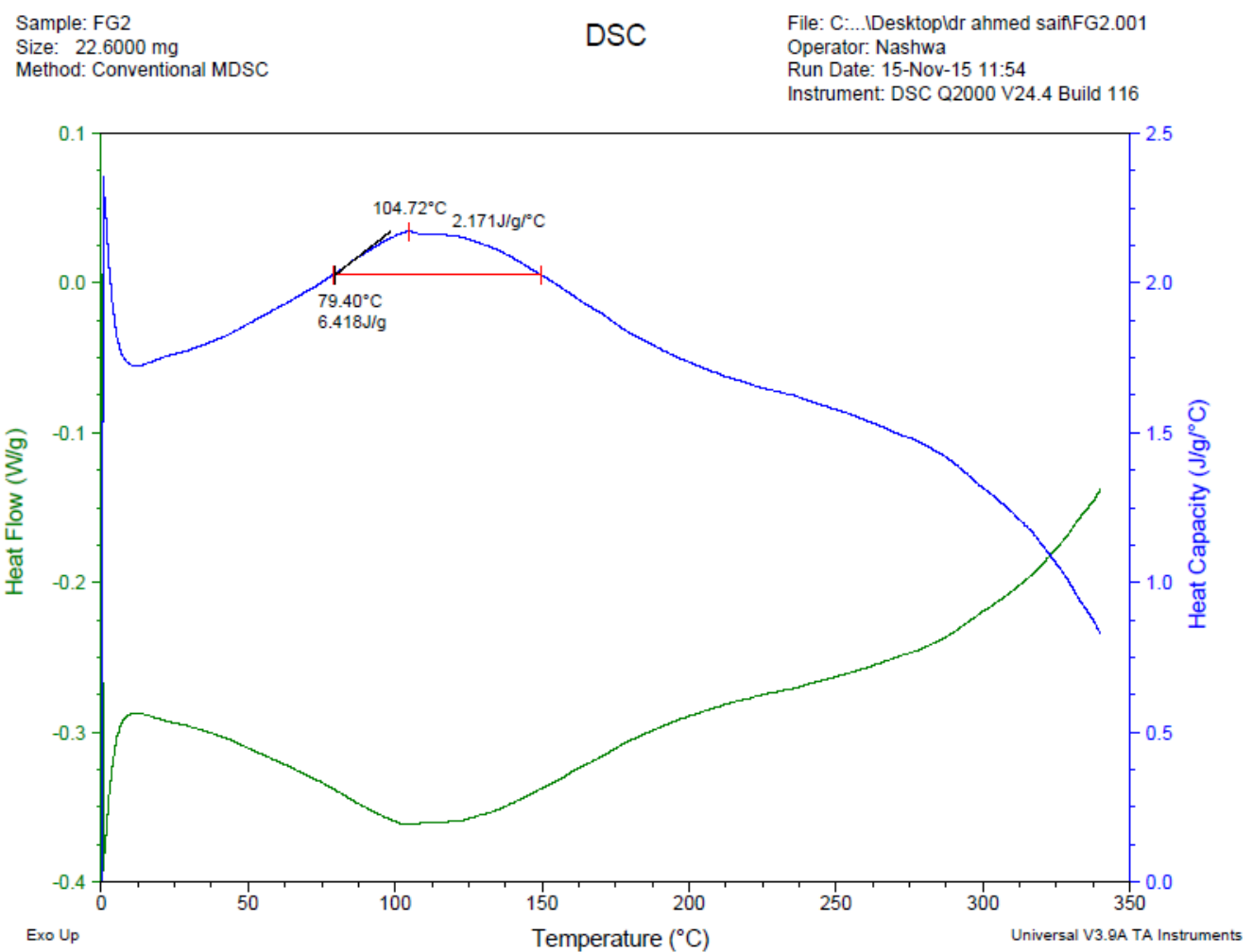

Fig.6. Specific heat and heat capacity for the Fiberglass. 


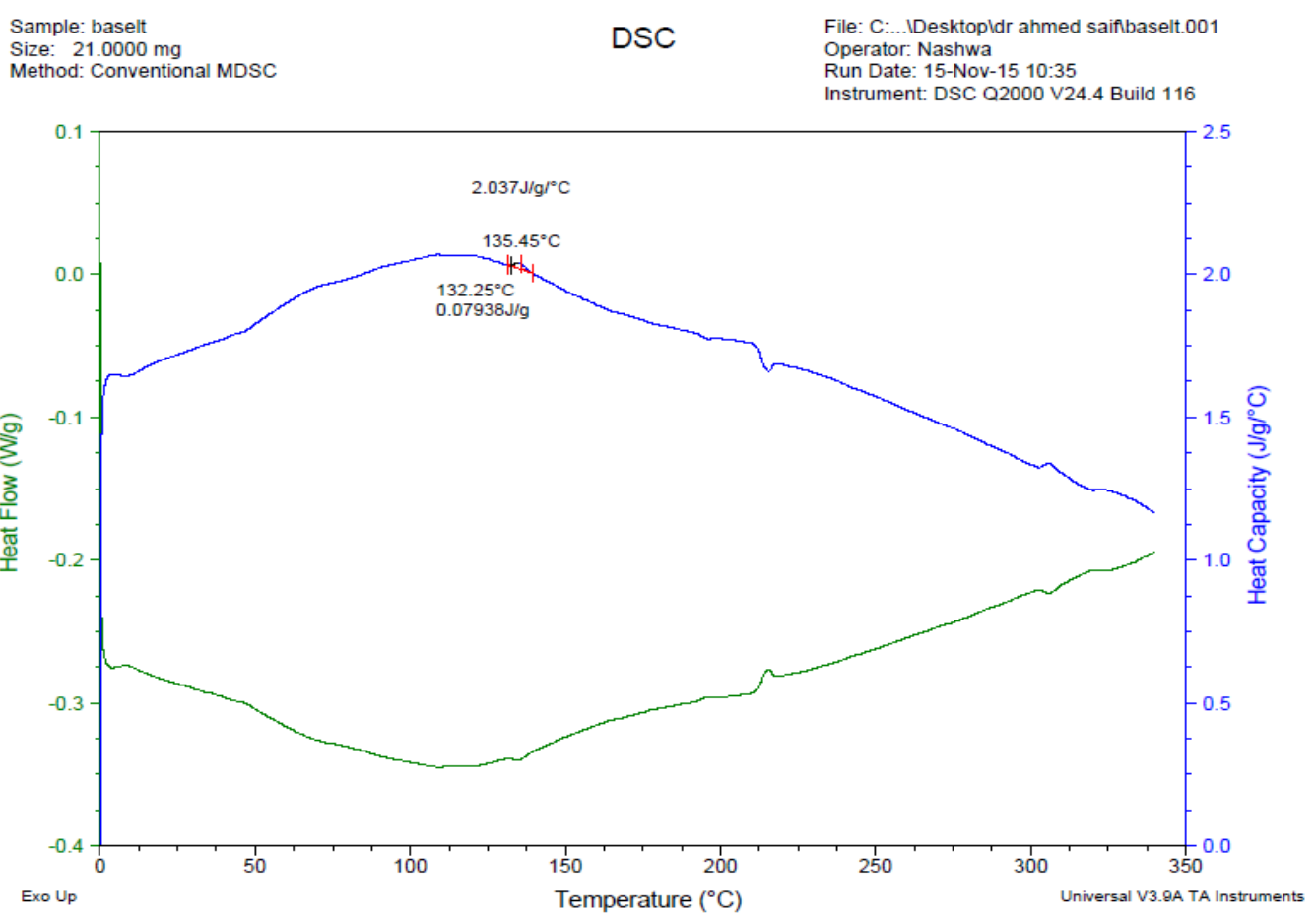

Fig.7. Specific heat and heat capacity for the Basalt.

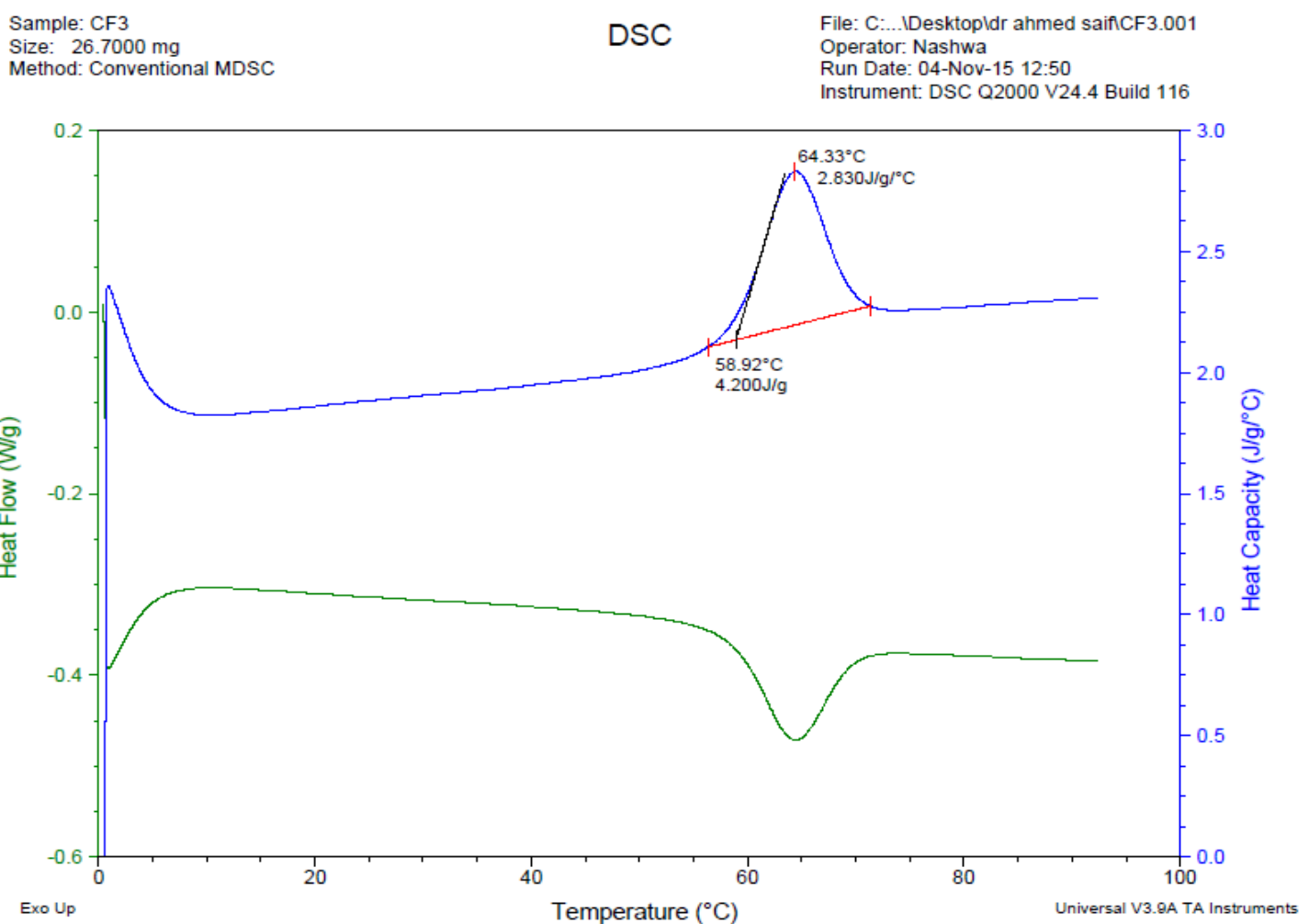

Fig.8. Specific heat and heat capacity for the Carbon / phenol. 


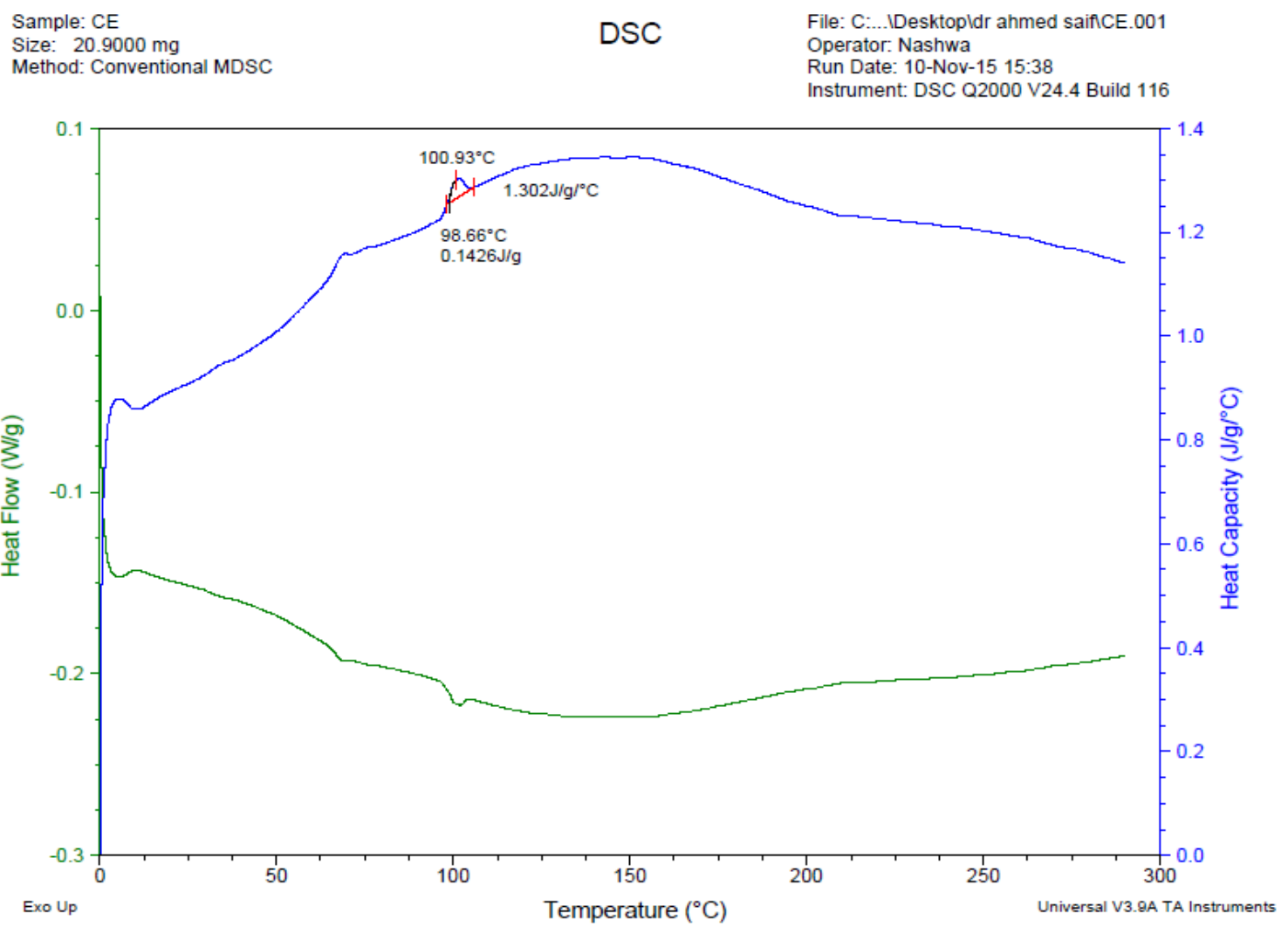

Fig.9. Specific heat and heat capacity for the Carbon/epoxy.

\section{Results of CTE}

For the thermal expansion coefficient the following Table 2 summarize the results while the figures 10:11 show the curves of this tests. It was expected that the results will be in a negative values for the phenolic based matrix composites [23, 24], while the composites with epoxy based matrix will be in a positive value.

Table 2. Results of CTE.

\begin{tabular}{|l|c|}
\hline \multicolumn{1}{|c|}{ Composite type } & CTE $\mu \mathrm{m} / \mathrm{m}^{\circ} \mathrm{C}$ \\
\hline Basalt / phenol & -179.9 \\
\hline Fiber glass / phenol & -146.6 \\
\hline Carbon / phenol & -273.7 \\
\hline Carbon/ epoxy & 1049 \\
\hline
\end{tabular}

For the materials cured with the phenol the CTE values are negative as expected and published before, but when tracing the behavior of the composites we notice that the material (fiber) tends to expands while the phenol tends to retract at the range of temperature up to $300-400{ }^{\circ} \mathrm{C}$, after that the matrix (phenol) overcome the fiber and retract to a lower limits. This phenomenon is clear in both of the Basalt and fiber glass with the phenol as a matrix. 


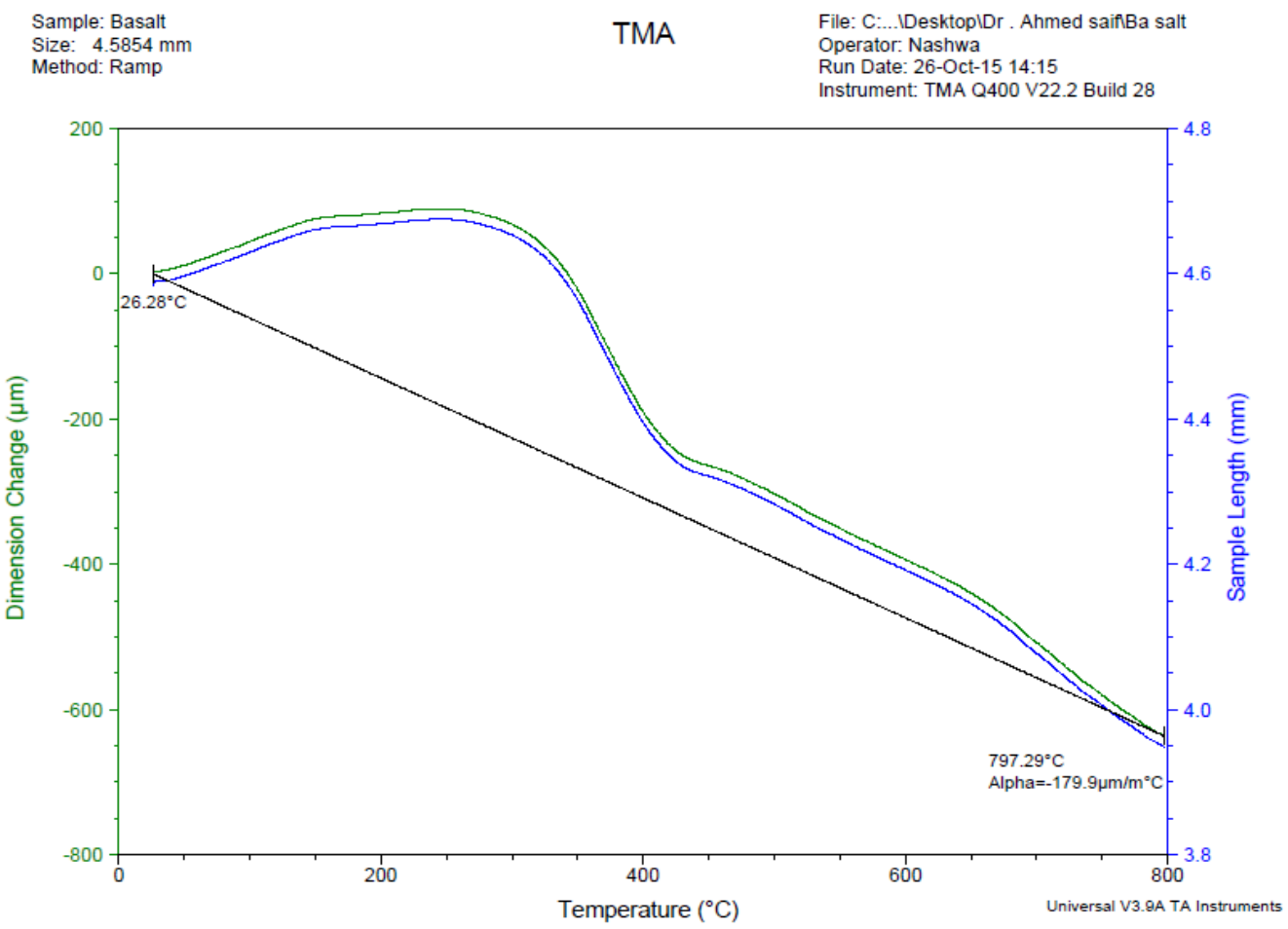

Fig. 10. CTE for Basalt.

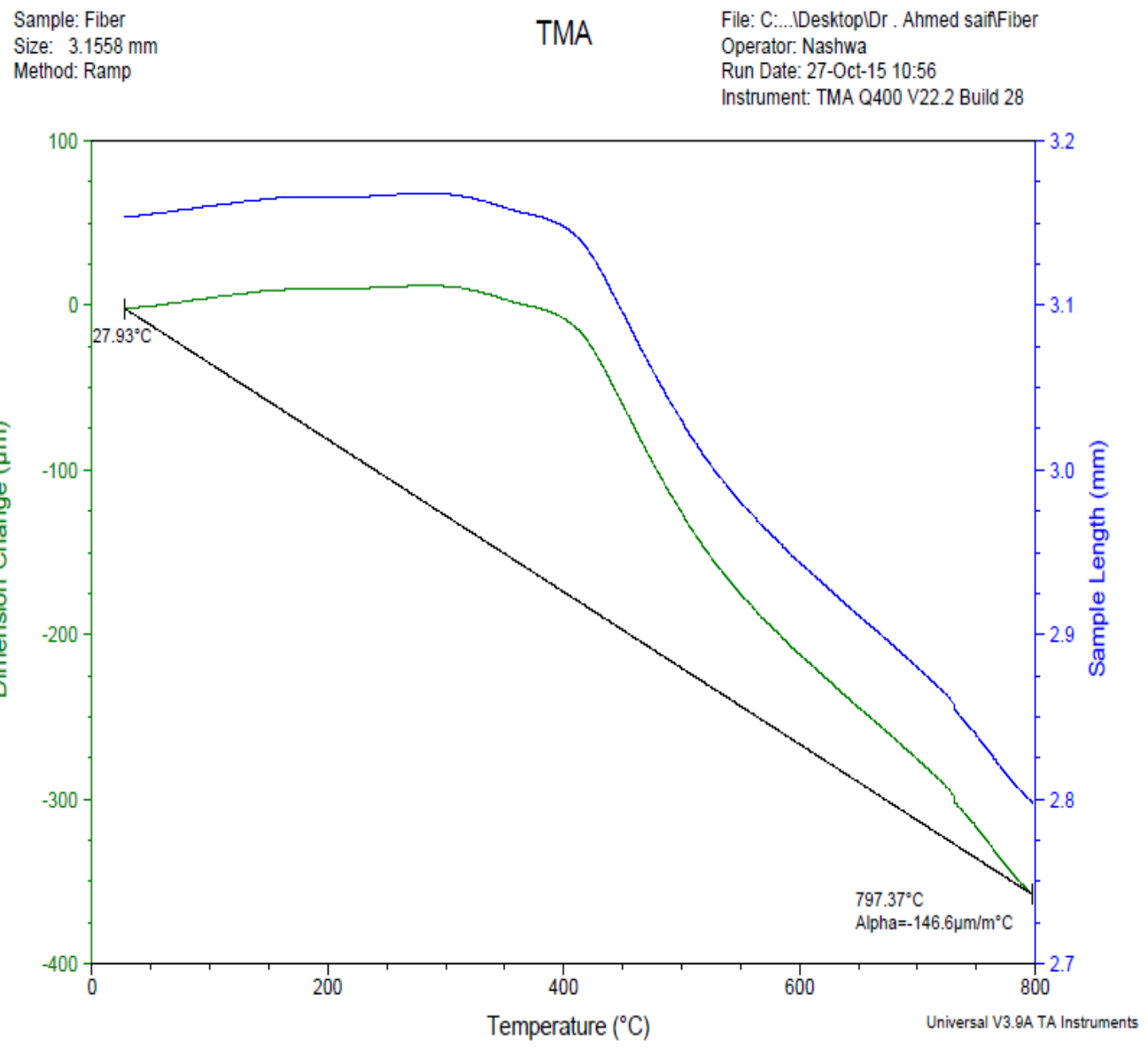

Fig. 11. CTE for Fiberglass. 


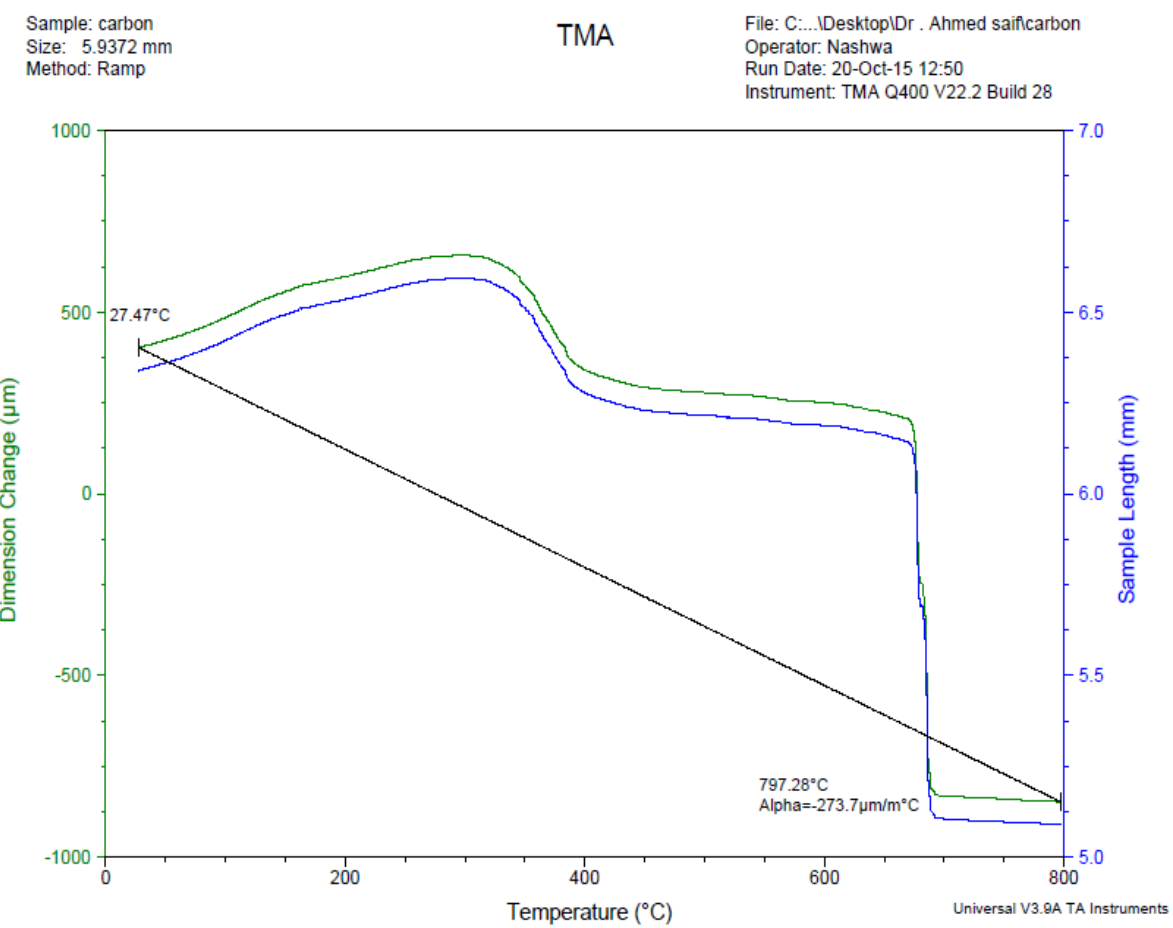

Fig. 12. CTE for Carbon fiber.

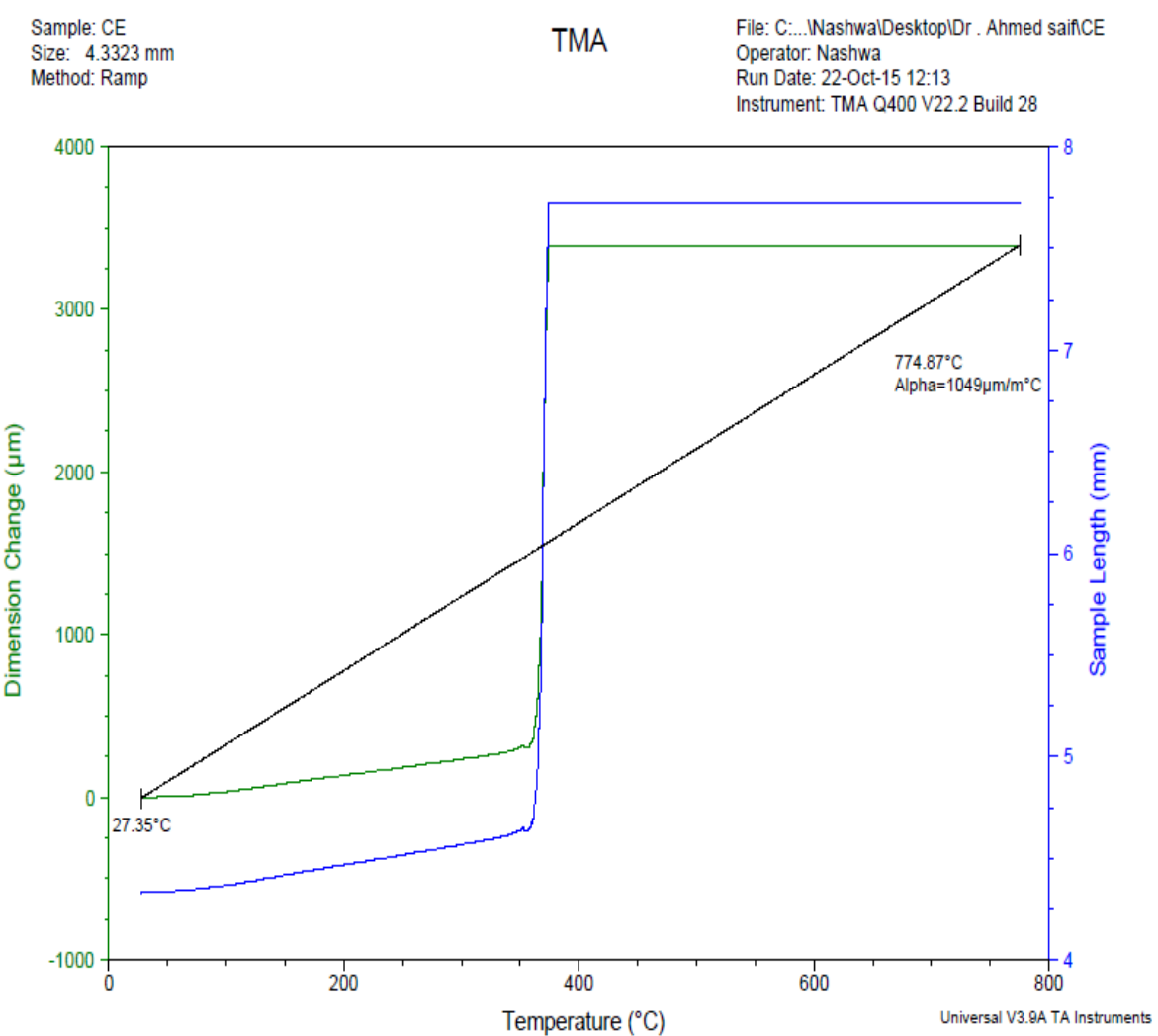

Fig. 13. CTE for carbon/epoxy. 
While the Carbon / phenol take the same behavior but when the temperature reached about $700{ }^{\circ} \mathrm{C}$ a sudden decrease of the CTE occurred perhaps, it is due to the separation between the fiber and the matrix.

This phenomenon occurred with the Carbon / Epoxy where the matrix tends to expand more than the fiber so the CTE increases and suddenly near the $400{ }^{\circ} \mathrm{C}$ a separation occurred and the matrix overcomes the fiber and increases the CTE.

The Carbon / Phenol has the lowest value of the CTE among those composites materials, with a value of $-273.7 \mu \mathrm{m} / \mathrm{m}^{\circ} \mathrm{C}$ while the Carbon / Epoxy has the highest CTE value with a value of $1049 \mu \mathrm{m} / \mathrm{m}^{\circ} \mathrm{C}$

\section{CONCLUSION}

Thermal properties of the selected materials are now known. The four materials have a very low thermal conductivity so they are used as thermal insulators.

The carbon fiber with phenol has the lowest thermal conductivity among those composite materials with $\mathrm{K}=0.159 \mathrm{w} / \mathrm{m}{ }^{\circ} \mathrm{C}$ while the carbon fiber with epoxy has the highest value of thermal conductivity with $\mathrm{K}=0.1942 \mathrm{w} / \mathrm{m}{ }^{\circ} \mathrm{C}$.

For the thermal expansion coefficient, the phenol based composites has a very small negative value of the CTE and this is also required in using those materials as insulators. While the Epoxy based composite has a very small positive value of CTE. Among those selected composed materials, Carbon / Phenol has a lowest value of CTE while Carbon / Epoxy has a highest value of CTE.

\section{REFERENCES}

[1] Luo Ry Friction "performance of $\mathrm{C} / \mathrm{C}$ composites prepared using rapid directional diffused CVI processes" Carbon 2002,40.1279-85.

[2] Siron O, Chollon G,Tsuda H, Yamauchi H, Maeda K, Kosaka K," Microstructural and mechanical properties of filler-added coal-tar pitchbased $\mathrm{C} / \mathrm{C}$ composites the damage and fraction process in correction with AE wave form parameters". Carbon 2000;38:1369-89.

[3] Ruiying Luo, Et al "Thermophysical properties of carbon/carbon composites and physical mechanism of thermal expansion and thermal conductivity "Carbon 42 (2004) 2887-2895.

[4] Bahramian AR, Kokabi M. "Ablation mechanism of polymer layered silicate nanocomposite heat shield." Hazard Mater 2009; 166(1):445-54.

[5] Kim ES, Kim EJ, Shim JH, Yoon J-S. "Thermal stability and ablation properties of silicon rubber composites." Appl Polym Sci 2008; 110:126370.

[6] Sing S, Guchhait PK, Bandyopadhyay GG, Chaki TK. "Development of polyimide- nanosilica filled EPDM based light rocket motor insulator compound influence of polyimide nanosilica loading on thermal, ablation, and mechanical properties". Composites: Part A 2013, 8:15-44. 
[7] Eslami, Z., Yazdani, F., Mirzapour, M.A., Thermal and mechanical properties of phenolic based composites reinforced by carbon fibres and multiwall carbon nanotubes, Composites: Part A (2015) S1359835X(15)00026-3.

[8] ASTM Standard C177-04, Standard Test Method for Steady-state Heat Flux Measurements and Thermal Transmission Properties by Means of the Guarded-Hot-Plate Apparatus. (ASTM, Philadelphia, 2004).

[9] ASTM Standard C518-04, Standard Test Method for Steady-state Thermal Transmission Properties by Means of the Heat Flow Meter Apparatus. (ASTM, Philadelphia, 2004).

[10] ISO Standard 8301, Thermal Insulation, Determination of Steady-state ThermalResistance and Related Properties, Heat Flow Meter Apparatus. (ISO, Geneva, Switzerland,1991).

[11] R.E. Taylor, J.Gembarovic, K.D. Maglic, in Characterization ofMaterials, vol. 1, ed. by E.N. Kaufman (John Wiley \& Sons, New York, 2003), p. 663.

[12] P. Andersson, G. Backstrom, Rev. Sci. Instrum. 47, 205 (1976).

[13] S.E. Gustafsson, Rev. Sci. Instrum. 62, 797 (1991).

[14] R.R. Bittle, R.E. Taylor, in Thermal Conductivity 18, ed. by R. Ashworth, D.R. Smith (Plenum, New York, 1984), pp. 379-390.

[16] Jozef Gembarovic - Raymond E. Taylor "A Method for Thermal Diffusivity Determination of Thermal Insulators" Int J Thermophys (2007) 28:21642175.

[17] R.L. Blaine and S.M. Marcus, "Derivation of Temperature Modulated DSC Thermal Conductivity Equations", Journal of Thermal Analysis, 1998, 54, pp. 467-476.

[18] S.M. Marcus and R.L. Blaine, "Thermal Conductivity of Polymers, Glasses and Ceramics by Modulated DSC", TA Instruments TA086.

[19] Thermal Analysis Review: Generic Definition for DSC, TA Instruments Publication TA 081.

[20] ASTM Test Method E1225 "Thermal Conductivity of Solids by Means of the Guarded- comparative-Longitudinal Heat Flow Technique", Annual Book of ASTM Standards, Vol. 14.02.

[21] E1952, "Method for Thermal Conductivity and Thermal Diffusivity by Modulated Temperature Differential Scanning Calorimetry", ASTM International, West Conshohocken, PA.

[22] S.M. Marcus and R.L. Blaine, "Thermal Conductivity of Polymers, Glasses and Ceramics by Modulated DSC", Thermochimica Acta, 1994, 243, pp. 231-239.

[23] Els Verdonck, Gunther Dreezen "Thermal Conductivity Measurements of Conductive Epoxy Adhesives by MDSC".

[24] B.N. Rath, S.J. Ghanwat, Santu Kaity, Chandan Danani, R.V. Kulkarni, V.D. Alur, D. Sathiyamoorthy, and S. Anantharaman "Thermal Conductivity of Composites of Beryllia and Lithium Titanate" ASM International published online May 31, 2013-10.1007/s11665-013-0606-z.

[25] Ruiying Luo et al "Thermophysical properties of carbon/carbon composites and physical mechanism of thermal expansion and thermal conductivity" Carbon 42 (2004) 2887-2895. 